\title{
High Prevalence of Hypertension in Ethiopian and Non-Ethiopian HIV-Infected Adults
}

\author{
Maya Korem, ${ }^{1}$ Tali Wallach, ${ }^{2}$ Michael Bursztyn, ${ }^{3}$ \\ Shlomo Maayan, ${ }^{4}$ and Karen Olshtain-Pops $\mathbb{1}^{1}$ \\ ${ }^{1}$ AIDS Unit, Department of Clinical Microbiology and Infectious Diseases, Hadassah-Hebrew University Medical Center, \\ Jerusalem, Israel \\ ${ }^{2}$ Department of Pediatrics, Kaplan Medical Center, Rehovot, Israel \\ ${ }^{3}$ Hypertension Unit, Department of Medicine, Hadassah-Hebrew University Medical Center, Mount Scopus, Jerusalem, Israel \\ ${ }^{4}$ Infectious Diseases and Infection Control Unit, Barzilai Medical Center, Ashkelon, Israel
}

Correspondence should be addressed to Karen Olshtain-Pops; kerenop@hadassah.org.il

Received 28 November 2017; Accepted 3 January 2018; Published 29 January 2018

Academic Editor: Roberto Pontremoli

Copyright (C) 2018 Maya Korem et al. This is an open access article distributed under the Creative Commons Attribution License, which permits unrestricted use, distribution, and reproduction in any medium, provided the original work is properly cited.

Objectives. Prevalence of hypertension has not been studied in the Ethiopian HIV-infected population, which represents $60 \%$ of the patients in our AIDS unit. Our aim was to identify risk factors and characterize the prevalence of hypertension in the population monitored at our unit. Methods. A retrospective chart review categorized subjects according to their blood pressure levels. Hypertension prevalence was determined and stratified according to variables perceived to contribute to elevated blood pressure. Results. The prevalence of hypertension in our study population was significantly higher compared to the general population $(53 \%$ versus $20 \%, P<0.0001)$ and was associated with known risk factors and not with patients' viral load and CD4 levels. Ethiopian HIV-infected adults had a prominently higher rate of blood pressure rise over time as compared to nonEthiopians $(P=0.016)$. Conclusions. The high prevalence of hypertension in this cohort and the rapid increase in blood pressure in Ethiopians are alarming. We could not attribute high prevalence to HIV-related factors and we presume it is part of the metabolic syndrome. The lifelong cardiovascular risk associated with HIV infection mandates hypertension screening and close monitoring in this population.

\section{Introduction}

The increased use of highly active antiretroviral therapy (HAART) in recent decades has led to a reduction in morbidity and mortality among people living with Human Immunodeficiency Virus (HIV) and has modified the course of HIV to a chronic infection with long-term complications, one of which is cardiovascular disease (CVD) $[1,2]$. Among HIV-infected individuals, CVD is a main cause of morbidity and mortality, comprising $10 \%$ of non-AIDS-related mortalities [3].

The increased risk of CVD is attributed to a combination of factors. Prolonged viremia is associated with elevated systemic inflammatory markers [4-6], hypercoagulation, damage to the endothelium [7], and premature atherosclerosis [8]. Prolonged HAART administration is associated with a linear increase in cardiovascular-related mortality for up to 5 years of HAART exposure $[9,10]$. This increase is related to the occurrence of lipodystrophy and metabolic derangements such as elevated cholesterol and triglyceride levels [11], insulin resistance, and impaired glucose tolerance $[9,10,12]$.

Fifty percent of coronary heart disease in developed countries is attributed to hypertension (HTN) [13]. HTN is increased in subjects with diabetes and dyslipidemia, which are more prevalent among HIV-infected individuals than in the general population $[3,14,15]$, and has become a potentially significant cause of morbidity in this population [16]. HTN in HIV-infected adults is associated with a higher frequency of persistent proteinuria, coronary heart disease, and myocardial infarction compared to nonhypertensive HIV-infected subjects [17]. 
The reported prevalence of HTN in HIV-infected adults shows great variance. It has been described as ranging from $8 \%$ to $34 \%[18,19]$ and was not found to be consistently higher than the levels found in matched HIV-negative adults [20]. An increased incidence of HTN was observed in HIVinfected adults treated with HAART for 48 weeks, as compared with HIV-infected HAART-naïve adults (26\% versus $7 \%$, resp.) [19]. In a recent meta-analysis of seven hypertension studies, the prevalence of abnormal diurnal blood pressure (BP) pattern that may contribute to the high CVD risk ranged from 29 to $82 \%$ among $\mathrm{HIV}$-infected individuals, compared to $15-53 \%$ in their HIV-negative counterparts [21].

Ethnic origin is a known factor affecting BP. Numerous studies conducted in the US found increased incidence and severity of HTN in African Americans compared with Caucasians $[22,23]$. The Ethiopian population is Semitic in origin and not frequently studied in HTN trials. A large meta-analysis of HTN in Equatorial African countries, which included studies from 1998 to 2008, estimated the incidence of HTN in Ethiopia as $10.6 \%$ [24]. In a study conducted in young Ethiopian immigrants in Israel, BP was significantly higher among young male Ethiopian immigrants compared with a group of Israeli students, despite a dramatically lower body mass index (BMI). In addition, the prevalence of HTN was higher in Ethiopian immigrants after 2 years of residence in Israel, compared to $<3$ months' residency in the same boarding schools [25].

The HIV unit at the Hadassah Medical Center is unique in that Ethiopian immigrants constitute $60 \%$ of the patients monitored in the clinic. This high rate allows for a HTN evaluation study in this population.

The goal of this retrospective study was to estimate the prevalence of elevated blood pressure (BP) among our cohort of HIV-infected adults and to compare its prevalence in Ethiopians and non-Ethiopians. In addition, we aimed to identify risk factors for the occurrence of elevated BP. To our knowledge, no previous studies have yet focused on BP in Ethiopian HIV-infected adults.

\section{Methods}

2.1. Study Population. The observational analytical crosssectional study was based on data retrieved from medical records of $\mathrm{HIV}$-infected adults aged $\geq 18$ years, who had been followed up at the AIDS unit in the outpatient clinic of the Hadassah (Ein Karem) Medical Center during the years 2000-2012. This adult HIV center, the only one in Jerusalem, monitors approximately $400 \mathrm{HIV}$-infected adults every 3 months. Each visit includes BP measurement, routine blood tests (including viral load and CD4 levels), an interview, and a physical examination.

As a control to our study population, we used BP data from a survey conducted by the Ministry of Health and the Central Bureau of Statistics in Israel during 2003-2004, which included approximately 10,000 participants (Supplement 1).

The research protocol for this study was approved by the Research Ethics Committee of the Hadassah-Hebrew University Medical Center.
2.2. Blood Pressure Measurement, Definition, and Collection. Blood pressure (BP) was measured at each visit in the clinic using a digital blood pressure machine (General Electric, DINAMAP ProCare 120). Measurements were taken by the staff nurse, after at least 5 minutes of rest, on the right upper arm, in the sitting position. BP levels were categorized into four levels, based on the seventh report of the Joint National Committee (JNC7) [26]: normal (systolic BP $<120$ $\mathrm{mm} \mathrm{Hg}$, diastolic < $80 \mathrm{~mm} \mathrm{Hg}$ ); prehypertension (systolic BP $120-139 \mathrm{~mm} \mathrm{Hg}$, diastolic BP $80-89 \mathrm{~mm} \mathrm{Hg}$ ); stage $1 \mathrm{HTN}$ (systolic BP 140-159 $\mathrm{mm} \mathrm{Hg}$, diastolic BP 90-99 mm Hg), and stage $2 \mathrm{HTN}$ (systolic BP $\geq 160 \mathrm{~mm} \mathrm{Hg}$, diastolic BP $\geq$ $100 \mathrm{~mm} \mathrm{Hg}$ ). The term HTN was generally used in this work for patients classified as HTN stage 1 or 2 as measured during two separate visits in the clinic over the follow-up period, or when antihypertensive medication was used for treating hypertension regardless of BP level in the clinic.

BP data from four time points during follow-up were collected from patient files: close to HIV diagnosis, at the time of the lowest recorded CD4 count, at the time the highest BP was recorded, and at the last visit.

\subsection{Clinical Data Collection and Risk Factor Definitions.} Clinical and laboratory data were obtained from the medical records. Basic clinical data included age, gender, ethnic origin, height, antiretroviral treatment, duration of HIV infection from the date of diagnosis, CVD risk factors, and family history of CVD. Laboratory data included CD4 cell counts, categorized as <200, 200-349, 350-500, and >500 cells/ $\mu$, and HIV-1 RNA or viral load, categorized as undetectable, $\leq 1000,>1000-10,000,>10,000-100,000, \geq 100,000$ copies $/ \mathrm{ml}$, HDL cholesterol, triglycerides, and fasting plasma glucose. Weight and all laboratory data were recorded at the same 4 time points as BP data. BMI $\geq 25 \mathrm{~kg} / \mathrm{m}^{2}$ was defined as overweight. Metabolic syndrome was defined according to the criteria of the National Cholesterol Education Program (NCEP) Adult Treatment Panel III (ATP III) 2005 [27]. In cases where diabetes mellitus had not been diagnosed, we used ADA criteria for the diagnosis [28]. Tobacco use was defined as any current or previous use. Family history of CVD was defined as development of atherosclerotic CVD in a firstdegree relative younger than 55 (males) or 65 (females).

2.4. Statistical Methods. All statistical analyses were conducted using SPSS software version 21.0. Statistical significance was assessed at the 0.05 level, and 2 -sided $P$ values are reported.

One-sample chi-square test was used to compare the prevalence of hypertension in the study group and in the general population. The $t$-test was used to compare quantitative variables between two independent groups. The association between two categorical variables was tested by a chi-square test and Fisher's exact test as appropriate.

The correlation between two quantitative variables was estimated by calculating the Pearson correlation coefficient.

Variables found to have a statistically significant association with the dependent variable (HTN) in a univariate analysis were examined in a multivariate model of logistic regression. To test which factors had impact on blood 
pressure over a period of time, a variability analysis model with repeated measurements was used.

\section{Results}

The study cohort consisted of 297 patients living with HIV, monitored at the Hadassah AIDS Center between January 2000 and December 2012. Within this group, 257 (86\%) patients were on HAART according to accepted guidelines [29].

3.1. Study Population Characteristics. Two hundred and seventy-eight subjects were included in the final analysis, representing $94 \%$ of the patients followed up at the clinic during the study period. The remaining 19 patients did not have sufficient follow-up information in their files. Mean age of study participants was 42 (range: $22-80$ years). Most subjects were of Ethiopian origin (172/278, 61.8\%). Overall, 157 (56\%) were men, but the proportion of men was significantly lower in Ethiopian $(73 / 172,42 \%)$ than in non-Ethiopian $(84 / 106,79 \%)$ patients $(P<0.001)$. Mean CD4 count at baseline for all participants was $350 \pm 255$ cells $/ \mathrm{ml} ; 30 \%$ had a CD4 count below 200 cells $/ \mathrm{ml}$. Mean follow-up time was 7 years.

3.2. Prevalence of HTN. Fifty-three percent (147/278) of the subjects were categorized as having HTN according to the highest recorded BP, which is significantly higher than the $20 \%$ prevalence in the general Israeli population, according to the national health survey conducted by the Central Bureau of Statistics (CBS) in 2003-2004 $(P<0.0001)$. This discrepancy remained significant when gender and age (21-44 and $\geq 45$ years) were stratified. BP data from the last visit in the clinic showed a lower prevalence of HTN, 63/278 $(22.6 \%)$, which is similar to the prevalence in the general population.

HTN rate was similar in Ethiopian and non-Ethiopian HIV-infected subjects (93/172, 54\% versus 54/106, 51\%, resp.).

\subsection{Prevalence of HTN by Stratified Characteristics and Risk} Factors. Table 1 describes the stratification of participants' characteristics according to three levels of blood pressure (normal, pre-HTN, and HTN) that were measured at two follow-up time points: (1) when the highest BP was measured and (2) at the last visit in the clinic.

The prevalence of HTN was significantly higher in males than in females. Subjects with metabolic syndrome or diabetes showed a greater propensity for HTN $(94.5 \%$ and $87.5 \%$, resp.; $P<0.001)$, as did obese $(68.8 \%, P<0.01)$ or older (73.6\%, $P<0.001)$ participants.

However, when multivariate analysis was used, the only factor that associated significantly with HTN was the presence of metabolic syndrome $(P<0.001)$.

3.4. Prevalence of HTN by Disease Parameters. No significant association was found between viral load or CD4 levels measured at nadir and HTN $(P>0.05)$ (Table 2).

The duration of HIV before HTN diagnosis was estimated using 2 parameters: (1) the duration of time measured between HIV diagnosis and maximal BP measurement and
(2) the CD4 level at nadir, which is considered an indirect measure of disease duration. Both parameters had no significant effect on the prevalence of HTN.

3.5. Impact of Ethnic Origin and the Time Elapsed from HIV Diagnosis to the Highest Recorded BP on the Prevalence of HTN. The highest BP was recorded on average 7 years (range: 1-20 years) after HIV diagnosis. The mean maximal BP was $141 / 83$, significantly higher than that measured at baseline (122/77, $P<0.001)$.

No significant correlation was found between duration of the period since HIV diagnosis to the highest recorded BP, or to HTN diagnosis, and there was no significant difference in HTN prevalence between Ethiopian and non-Ethiopian HIVinfected subjects between these two time points. However, we found a significant interaction between time and ethnic origin: the rate of diastolic and systolic BP rise over time was significantly higher in Ethiopian than in non-Ethiopian HIVinfected subjects $(P=0.016)$.

\section{Discussion}

This study describes the prevalence of HTN in HIV-infected adults in an urban setting in Israel, with a focus on patients of Ethiopian origin, a population that has not been thoroughly studied.

Prevalence of HTN in all study subjects was significantly higher among HIV-infected adults (53\%) compared to the general population $(20 \%, P<0.0001)$. Male gender and age were significantly associated with HTN, as reported for nonHIV populations [30]. This high prevalence was found at the point of the highest recorded BP, as well as at CD4 nadir. This finding is in concordance with results from a study conducted in Italy [31], which showed that the incidence of HTN is significantly higher among HIV-infected adults, compared to a control cohort of healthy blood donors (34.2\% and $11.2 \%$, resp.). The authors suggest that the higher resistance to insulin found among HIV-infected adults as compared with the controls (HOMA index $1.2 \pm 3.3$ versus $0.9 \pm 2$, resp.; $P<$ 0.001 ) could explain this finding. In addition, higher HOMA indices were found among HIV-infected adults with HTN as opposed to those without HTN $(3.7 \pm 1$ versus $1.2 \pm 3.1$, $P<0.001)$.

Other studies have also reported high rates of insulin resistance among HIV-infected adults treated with HAART $[32,33]$. Hyperinsulinemia contributes to HTN by several mechanisms, including increased effect of angiotensin II on aldosterone and vascular contraction [34]. It is also linked to the metabolic syndrome, a strong independent cardiovascular risk factor [35] with increased prevalence among HIVinfected adults [36]. Insulin resistance was also predictive of the development of hypertension in lean, young Ethiopian immigrants in Israel [37].

A correlation between HAART and increased prevalence of HTN in HIV-infected adults has been reported [31, 34]. In a study conducted in Spain [19], which included patients who began HAART, a statistically significant rise in systolic and diastolic BP was found after 48 weeks of treatment. However, we did not find a significant association between HAART and 
TABLE 1: Participants' characteristics by three levels of BP at two time points of follow-up.

\begin{tabular}{|c|c|c|c|c|c|c|}
\hline \multirow{3}{*}{ Characteristics } & \multicolumn{4}{|c|}{ Number of patients (\% of total cohort) } & \multirow{2}{*}{\multicolumn{2}{|c|}{ Last visit $\mathrm{BP}$}} \\
\hline & \multicolumn{3}{|c|}{ Highest BP } & \multirow[b]{2}{*}{ Normal } & & \\
\hline & Normal & Pre-HTN & HTN & & Pre-HTN & HTN \\
\hline \multicolumn{7}{|l|}{ Ethnicity } \\
\hline Ethiopian & $12(7)$ & $67(39)$ & $93(54)$ & $59(34.3)$ & $73(42.4)$ & $40(23.2)$ \\
\hline \multirow[t]{2}{*}{ Non-Ethiopian } & $2(1.9)$ & $50(47.2)$ & $54(51)$ & $33(31.1)$ & $50(47.2)$ & $23(21.7)$ \\
\hline & & & $P=0.2$ & & & $P=0.87$ \\
\hline \multicolumn{7}{|l|}{ Gender } \\
\hline Female & $9(7.4)$ & $61(50.4)$ & $51(42.2)$ & $51(42.1)$ & $50(41.3)$ & $20(16.5)$ \\
\hline \multirow[t]{2}{*}{ Male } & $5(3.2)$ & $56(35.7)$ & $96(61.2)$ & $41(26.1)$ & $73(46.4)$ & $43(27.3)$ \\
\hline & & & $P<0.01$ & & & $P<0.05$ \\
\hline \multicolumn{7}{|l|}{ Age (years) } \\
\hline $21-44$ & $10(5.4)$ & $94(51)$ & $80(44.1)$ & $74(39.5)$ & $77(41.1)$ & $36(19.2)$ \\
\hline \multirow[t]{2}{*}{$\geq 45$} & $4(4.2)$ & $23(24.4)$ & $67(71.2)$ & 18 (19.7) & $46(50.5)$ & $27(29.6)$ \\
\hline & & & $P<0.001$ & & & $P<0.01$ \\
\hline \multicolumn{7}{|l|}{ Overweight } \\
\hline No & $5(7.1)$ & $33(47.1)$ & $32(45.7)$ & $29(42)$ & $26(37.7)$ & $14(20.2)$ \\
\hline \multirow[t]{2}{*}{ Yes } & $0(0)$ & $15(31.3)$ & $63(68.8)$ & $8(16.7)$ & $24(50)$ & $16(33.3)$ \\
\hline & & & $P^{1}=0.01$ & & & $P^{1}=0.01$ \\
\hline \multicolumn{7}{|l|}{ Metabolic syndrome } \\
\hline No & $5(5.4)$ & $46(50)$ & $41(44.5)$ & $33(36.3)$ & $44(48.4)$ & $14(15.4)$ \\
\hline Yes & $0(0)$ & $1(5.6)$ & $17(94.5)$ & $0(0)$ & $6(33.3)$ & $12(66.7)$ \\
\hline \multirow[t]{2}{*}{ Diabetes mellitus } & $0(0)$ & $1(12.5)$ & $7(87.5)$ & $2(25)$ & $2(25)$ & $4(50)$ \\
\hline & & & $P<0.001$ & & & $P^{1}<0.001$ \\
\hline \multicolumn{7}{|c|}{ Family history of CVD } \\
\hline No & $5(4.9)$ & $45(43.7)$ & $53(51.4)$ & $34(33.3)$ & $46(45.1)$ & $22(21.5)$ \\
\hline \multirow[t]{2}{*}{ Yes } & $0(0)$ & $4(23.5)$ & $13(76.5)$ & $2(11.8)$ & $6(35.3)$ & $9(53)$ \\
\hline & & & $P^{1}=0.26$ & & & $P^{1}=0.02$ \\
\hline \multicolumn{7}{|l|}{ Tobacco use } \\
\hline No & $1(3.1)$ & $16(50)$ & $15(46.8)$ & $14(43.8)$ & $13(40.6)$ & $5(15.6)$ \\
\hline \multirow[t]{2}{*}{ Yes } & $5(5.6)$ & $35(38.9)$ & $50(55.5)$ & $25(28.1)$ & $39(43.8)$ & $25(28.1)$ \\
\hline & & & $P^{1}=0.3$ & & & $P^{1}=0.41$ \\
\hline \multicolumn{7}{|l|}{ CD4 count (cells/ $\mu \mathrm{l})$} \\
\hline$\leq 200(n=131)$ & $8(6.1)$ & $51(38.9)$ & $72(54.9)$ & $46(34.3)$ & $56(42.7)$ & $30(23)$ \\
\hline \multirow[t]{2}{*}{$>200(n=147)$} & $6(4)$ & $66(44.8)$ & $75(51)$ & $46(29.9)$ & $67(47.6)$ & $33(22.4)$ \\
\hline & & & $P=0.64$ & & & $P=0.64$ \\
\hline \multicolumn{7}{|l|}{ Use of HAART } \\
\hline No $(n=38)$ & $4(10.8)$ & $16(43.2)$ & $17(45.9)$ & $15(33.3)$ & $22(48.8)$ & $8(17.7)$ \\
\hline \multirow[t]{2}{*}{ Yes $(n=240)$} & $10(4.1)$ & $101(41.9)$ & $130(53.9)$ & $77(33)$ & $101(43.3)$ & $55(23.6)$ \\
\hline & & & $P=0.38$ & & & $P=0.69$ \\
\hline
\end{tabular}

${ }^{1}$ Fisher's exact test was performed for low prevalence; BP: blood pressure; HTN: hypertension; CVD: cardiovascular disease; HAART: highly active antiretroviral treatment.

the presence of HTN. The lack of agreement among the studies may be related to the inclusion of HIV-infected adults with initially lower CD4 values in other studies [19]. Commencing HAART in these subjects may have led to weight gain and consequently to HTN. Another explanation is the low rate of HIV-infected adults that were not treated with HAART in our study.

We found obesity, family history, advanced age, diabetes, and metabolic syndrome to be associated with HTN. These are the known risk factors for HTN, closely related to insulin resistance in the general population [38], and therefore support the reliability of our findings. Yet, we could not point to a clear reason for the higher prevalence of HTN in this population. Possibly, the HIV associated chronic inflammatory process is responsible for an increased prevalence of the metabolic syndrome in HIV patients and for the higher prevalence of HTN found in this cohort, which we assume is part of the metabolic syndrome. 
TABLE 2: Prevalence of HTN measured at the time of the lowest recorded CD4 count according to categorized CD4 and viral load levels $(P>0.05)$

\begin{tabular}{|c|c|c|c|}
\hline \multicolumn{4}{|c|}{ Number of patients (\% of total cohort) } \\
\hline & \multicolumn{2}{|c|}{ BP status } & \multirow[t]{2}{*}{ Total } \\
\hline & No HTN & $\mathrm{HTN}$ & \\
\hline \multicolumn{4}{|l|}{ CD4 count (cells/ $\mu \mathrm{l})$} \\
\hline$<200$ & $70(47.9)$ & $76(52)$ & $146(100)$ \\
\hline $200-349$ & $37(43.5)$ & $48(56.5)$ & $85(100)$ \\
\hline $350-499$ & $15(50)$ & $15(50)$ & $30(100)$ \\
\hline$\geq 500$ & $9(53)$ & $8(47)$ & $17(100)$ \\
\hline Total & $131(47.1)$ & $147(52.8)$ & $278(100)$ \\
\hline \multicolumn{4}{|l|}{$\mathrm{VL}^{1}($ copies $/ \mathrm{ml})$} \\
\hline$<50$ & $23(40.4)$ & $34(59.6)$ & 57 \\
\hline $50-1000$ & $9(39.1)$ & $14(60.9)$ & 23 \\
\hline$>1000-10,000$ & $16(42.1)$ & $22(57.9)$ & 38 \\
\hline$>10,000-100,000$ & $34(54.8)$ & $28(45.2)$ & 62 \\
\hline$>100,000$ & $31(48.4)$ & $33(51.6)$ & 64 \\
\hline Total & 113 & 131 & $244(100)$ \\
\hline
\end{tabular}

${ }^{1}$ Data was missing for $n=34$; BP: blood pressure; HTN: hypertension; VL: viral load.

A recent study [39] found nadir CD4 values below 50 cells $/ \mu \mathrm{l}$ to be an independent risk factor for the development of HTN in HIV-infected adults. Possible explanations for these results are inflammation of the small intestine found at low CD4 levels (HIV enteropathy) with activation of the immune system and release of inflammatory mediators, contributing to elevation of angiotensin II and salt accumulation [40,41]. We did not find nadir CD4 values to be associated with a high prevalence of HTN, possibly because we categorized CD4 counts to higher values, which were chosen according to the guidelines for starting HAART therapy [29].

In our cohort, no association was found between viral load or CD4 levels at nadir and the presence of HTN. Both parameters are indirect measures of disease duration and do not accurately reflect the duration of viremia.

Unlike results from other studies [22, 23], no significant correlation was found between ethnic origin and the presence of HTN. However, the rate of BP increase over time was significantly higher in Ethiopian than in non-Ethiopian HIVinfected subjects. This finding may be related to lifestyle and dietary modifications as a result of immigration and is supported by a research conducted in Israel among Ethiopian adolescents, which pointed to the impact of an adopted new lifestyle on BP [25]. It is important to note that in this study the proportion of male patients of Ethiopian origin was significantly lower than in the non-Ethiopian group ( $42 \%$ versus $79 \%, P<0.001)$. Since male patients had a significantly higher prevalence of HTN, this may have resulted in an underestimation of HTN prevalence among patients of Ethiopian origin.

A limitation of this study resides in its retrospective nature, which prevents determining the cause of HTN. Current guidelines define HTN as the average of two or more properly measured readings at each of two or more office visits after an initial screen [26]. With multiple measurements, high BP tends to decrease during subsequent visits
$[26,42]$. However, elevated BP may be predictive of future BP elevations [43], and the high prevalence of HTN was recorded at two different time points under identical conditions during the whole follow-up period. This somewhat reduces the probability of inconsistency between measurements. Although HTN data obtained at the last visit was similar to the values in the general population $(63 / 278,22.6 \%)$, this may have been the result of antihypertensive medication provided to patients with high BP during follow-up.

\section{Conclusions}

HIV-infected adults have an increased risk of cardiovascular morbidity and related risk factors, such as the metabolic syndrome.

Our study reports increased prevalence of HTN in this population in comparison with the general population and points to an increased rate of BP rise in Ethiopian HIVinfected adults. Despite the lack of a clear explanation for this finding, we postulate that prolonged replication of the virus and the resulting inflammatory process may lead to metabolic syndrome and related hypertension. Raising awareness of the treating physicians to the significance of this risk factor will allow better monitoring and earlier treatment, reducing the impact of this risk factor on cardiovascular mortality.

\section{Conflicts of Interest}

The authors declare no conflicts of interest regarding the publication of this paper.

\section{Acknowledgments}

Michele Hauzi-Bashan, Head Nurse at the Hadassah AIDS Center, performed all blood pressure measurements, as part of her routine clinical responsibilities. 


\section{Supplementary Materials}

Supplement 1: blood pressure data from a survey conducted by the Ministry of Health and the Central Bureau of Statistics in Israel during 2003-2004. (Supplementary Materials)

\section{References}

[1] J. S. Currier, A. Taylor, F. Boyd et al., "Coronary heart disease in HIV-infected individuals," Journal of Acquired Immune Deficiency Syndromes, vol. 33, no. 4, pp. 506-512, 2003.

[2] P. Y. Hsue, K. Squires, A. F. Bolger et al., "Screening and assessment of coronary heart disease in HIV-infected patients," Circulation, vol. 118, no. 2, pp. e41-e47, 2008.

[3] V. A. Triant, H. Lee, C. Hadigan, and S. K. Grinspoon, "Increased acute myocardial infarction rates and cardiovascular risk factors among patients with human immunodeficiency virus disease," The Journal of Clinical Endocrinology \& Metabolism, vol. 92, no. 7, pp. 2506-2512, 2007.

[4] G. K. Hansson, "Inflammation, atherosclerosis, and coronary artery disease," The New England Journal of Medicine, vol. 352, no. 16, pp. 1685-1695, 2005.

[5] J. S. Reingold, C. Wanke, D. P. Kotler et al., "Association of HIV infection and HIV/HCV coinfection with C-reactive protein levels: The fat redistribution and metabolic change in HIV infection (FRAM) study," Journal of Acquired Immune Deficiency Syndromes, vol. 48, no. 2, pp. 142-148, 2008.

[6] P. C. Tien, A. I. Choi, A. R. Zolopa et al., "Inflammation and mortality in HIV-infected adults: Analysis of the FRAM study cohort," Journal of Acquired Immune Deficiency Syndromes, vol. 55, no. 3, pp. 316-322, 2010.

[7] J. Baker, H. Quick, K. H. Hullsiek et al., "Interleukin-6 and ddimer levels are associated with vascular dysfunction in patients with untreated HIV infection," HIV Medicine, vol. 11, no. 9, pp. 608-609, 2010.

[8] S. Subramanian, A. Tawakol, T. H. Burdo et al., "Arterial inflammation in patients with HIV," Journal of the American Medical Association, vol. 308, no. 4, pp. 379-386, 2012.

[9] N. Friis-Møller, C. A. Sabin, R. Weber et al., "Combination antiretroviral therapy and the risk of myocardial infarction," The New England Journal of Medicine, vol. 349, pp. 1993-2003, 2003.

[10] A. Carr, K. Samaras, A. Thorisdottir, G. R. Kaufmann, D. J. Chisholm, and D. A. Cooper, "Diagnosis, prediction, and natural course of HIV-1 protease-inhibitor-associated lipodystrophy, hyperlipidaemia, and diabetes mellitus: a cohort study," The Lancet, vol. 353, no. 9170, pp. 2093-2099, 1999.

[11] E. Fontas, F. Van Leth, C. A. Sabin et al., "Lipid profiles in HIVinfected patients receiving combination antiretroviral therapy: are different antiretroviral drugs associated with different lipid profiles?" The Journal of Infectious Diseases, vol. 189, no. 6, pp. 1056-1074, 2004.

[12] G. Behrens, A. Dejam, H. Schmidt et al., "Impaired glucose tolerance, beta cell function and lipid metabolism in HIV patients under treatment with protease inhibitors," AIDS, vol. 13, no. 10, pp. F63-F70, 1999.

[13] M. Rayner, S. Allender, and P. Scarborough, "Cardiovascular disease in Europe," European Journal of Cardiovascular Prevention \& Rehabilitation, vol. 16, supplement 2, pp. S43-S47, 2009.

[14] C. Grunfeld, M. Pang, W. Doerrler, J. K. Shigenaga, P. Jensen, and K. R. Feingold, "Lipids, lipoproteins, triglyceride clearance, and cytokines in human immunodeficiency virus infection and the acquired immunodeficiency syndrome," The Journal of Clinical Endocrinology \& Metabolism, vol. 74, no. 5, pp. 10451052, 1992.

[15] T. T. Brown, S. R. Cole, X. Li et al., "Antiretroviral therapy and the prevalence and incidence of diabetes mellitus in the multicenter AIDS cohort study," JAMA Internal Medicine, vol. 165, no. 10, pp. 1179-1184, 2005.

[16] F. J. Palella Jr., K. M. Delaney, A. C. Moorman et al., "Declining morbidity and mortality among patients with advanced human immunodeficiency virus infection," The New England Journal of Medicine, vol. 338, no. 13, pp. 853-860, 1998.

[17] O. Jung, M. Bickel, T. Ditting et al., "Hypertension in HIV-1infected patients and its impact on renal and cardiovascular integrity," Nephrology Dialysis Transplantation, vol. 19, no. 9, pp. 2250-2258, 2004.

[18] M. Baekken, I. Os, L. Sandvik, and O. Oektedalen, "Hypertension in an urban HIV-positive population compared with the general population: Influence of combination antiretroviral therapy," Journal of Hypertension, vol. 26, no. 11, pp. 2126-2133, 2008.

[19] R. Palacios, J. Santos, A. García et al., "Impact of highly active antiretroviral therapy on blood pressure in HIV-infected patients. A prospective study in a cohort of naive patients," HIV Medicine, vol. 7, no. 1, pp. 10-15, 2006.

[20] B. M. Bergersen, L. Sandvik, O. Dunlop, K. Birkeland, and J. N. Bruun, "Prevalence of Hypertension in HIV-Positive Patients on Highly Active Retroviral Therapy (HAART) compared with HAART-Naïve and HIV-Negative Controls: results from a Norwegian Study of 721 patients," European Journal of Clinical Microbiology \& Infectious Diseases, vol. 22, no. 12, pp. 731-736, 2003.

[21] S. T. Kent, S. G. Bromfield, G. A. Burkholder et al., "Ambulatory blood pressure monitoring in individuals with HIV: A systematic review and meta-analysis," PLoS ONE, vol. 11, no. 2, Article ID e0148920, 2016.

[22] A. P. Carson, G. Howard, G. L. Burke, S. Shea, E. B. Levitan, and P. Muntner, "Ethnic differences in hypertension incidence among middle-aged and older adults: The multi-ethnic study of atherosclerosis," Hypertension, vol. 57, no. 6, pp. 1101-1107, 2011.

[23] H. Kramer, C. Han, W. Post et al., "Racial/ethnic differences in hypertension and hypertension treatment and control in the Multi-Ethnic Study of Atherosclerosis (MESA)," American Journal of Hypertension, vol. 17, no. 10, pp. 963-970, 2004.

[24] M. Twagirumukiza, D. De Bacquer, J. G. Kips, G. de Backer, R. V. Stichele, and L. M. van Bortel, "Current and projected prevalence of arterial hypertension in sub-Saharan Africa by sex, age and habitat: an estimate from population studies," Journal of Hypertension, vol. 29, no. 7, pp. 1243-1252, 2011.

[25] M. Bursztyn and I. Raz, "Blood pressure, glucose, insulin and lipids of young ethiopian recent immigrants to israel and in those resident for 2 years," Journal of Hypertension, vol. 11, no. 4, pp. 455-459, 1993.

[26] A. V. Chobanian, G. L. Bakris, H. R. Black et al., "The seventh report of the joint national committee on prevention, detection, evaluation, and treatment of high blood pressure: the JNC 7 report," The Journal of the American Medical Association, vol. 289, no. 19, pp. 2560-2572, 2003.

[27] S. M. Grundy, J. I. Cleeman, S. R. Daniels et al., "Diagnosis and management of the metabolic syndrome: an American Heart Association/National Heart, Lung, and Blood Institute scientific statement," Circulation, vol. 112, no. 17, pp. 2735-2752, 2005. 
[28] American Diabetes Association, "Diagnosis and classification of diabetes mellitus," Diabetes Care, vol. 33, supplement 1, pp. S62-S69, 2010.

[29] M. A. Thompson, J. A. Aberg, J. F. Hoy et al., "Antiretroviral treatment of adult HIV infection: 2012 recommendations of the International Antiviral Society-USA panel," The Journal of the American Medical Association, vol. 308, no. 4, pp. 387-402, 2012.

[30] D. E. Vance, M. Mugavero, J. Willig, J. L. Raper, and M. S. Saag, "Aging with HIV: a cross-sectional study of comorbidity prevalence and clinical characteristics across decades of life," Journal of the Association of Nurses in AIDS Care, vol. 22, no. 1, pp. 17-25, 2011.

[31] C. Gazzaruso, R. Bruno, A. Garzaniti et al., "Hypertension among HIV patients: prevalence and relationships to insulin resistance and metabolic syndrome," Journal of Hypertension, vol. 21, no. 7, pp. 1377-1382, 2003.

[32] M. Fantoni, C. Del Borgo, C. Autore, and G. Barbaro, "Metabolic disorders and cardiovascular risk in HIV-infected patients treated with antiretroviral agents," Italian Heart Journal, vol. 3, no. 5, pp. 294-299, 2002.

[33] S. Grinspoon, "Insulin resistance in the HIV-lipodystrophy syndrome," Trends in Endocrinology \& Metabolism, vol. 12, no. 9, pp. 413-419, 2001.

[34] N. Hejazi, M. S. Huang, K. G. Lin, and L. C. K. Choong, "Hypertension among HIV-infected adults receiving highly active antiretroviral therapy (HAART) in Malaysia," Global Journal of Health Science, vol. 6, no. 2, pp. 58-71, 2014.

[35] B. Isomaa, P. Almgren, T. Tuomi et al., "Cardiovascular morbidity and mortality associated with the metabolic syndrome," Diabetes Care, vol. 24, no. 4, pp. 683-689, 2001.

[36] C. Gazzaruso, P. Sacchi, A. Garzaniti, P. Fratino, R. Bruno, and G. Filice, "Prevalence of metabolic syndrome among HIV patients," Diabetes Care, vol. 25, no. 7, pp. 1253-1254, 2002.

[37] M. Bursztyn and I. Raz, "Prediction of hypertension by the insulinogenic index in young Ethiopian immigrants," Journal of Hypertension, vol. 13, no. 1, pp. 57-61, 1995.

[38] A. R. Dyer, K. Liu, M. Walsh, C. Kiefe, D. R. Jacobs Jr., and D. E. Bild, "Ten-year incidence of elevated blood pressure and its predictors: The CARDIA Study," Journal of Human Hypertension, vol. 13, no. 1, pp. 13-21, 1999.

[39] I. W. Manner, M. Trøseid, O. Oektedalen, M. Baekken, and I. Os, "Low nadir CD4 cell count predicts sustained hypertension in HIV-infected individuals," The Journal of Clinical Hypertension, vol. 15, no. 2, pp. 101-106, 2013.

[40] D. G. Harrison, T. J. Guzik, H. E. Lob et al., "Inflammation, immunity, and hypertension," Hypertension, vol. 57, no. 2, pp. 132-140, 2011.

[41] W. Jiang, M. M. Lederman, P. Hunt et al., "Plasma levels of bacterial DNA correlate with immune activation and the magnitude of immune restoration in persons with antiretroviraltreated HIV infection," The Journal of Infectious Diseases, vol. 199, no. 8, pp. 1177-1185, 2009.

[42] R. D. S. Watson, R. Lumb, M. A. Young, T. J. Stallard, P. Davies, and W. A. Littler, "Variation in cuff blood pressure in untreated outpatients with mild hypertension-implications for initiating antihypertensive treatment," Journal of Hypertension, vol. 5, no. 2, pp. 207-211, 1987.

[43] I. Bidlingmeyer, M. Burnier, M. Bidlingmeyer, B. Waeber, and H. R. Brunner, "Isolated office hypertension: A prehypertensive state?" Journal of Hypertension, vol. 14, no. 3, pp. 327-332, 1996. 


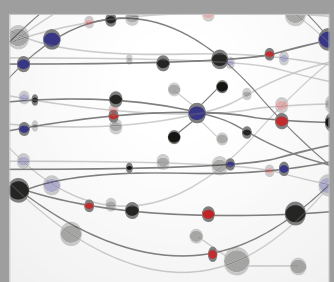

The Scientific World Journal
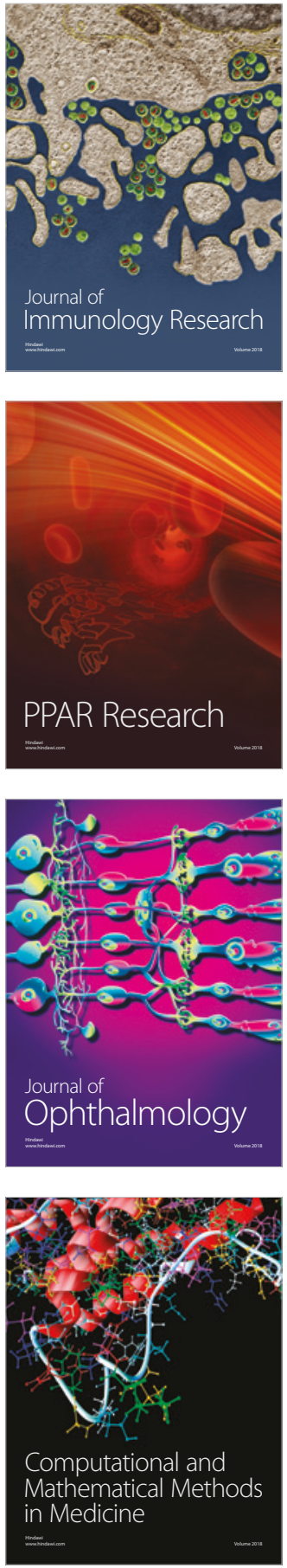

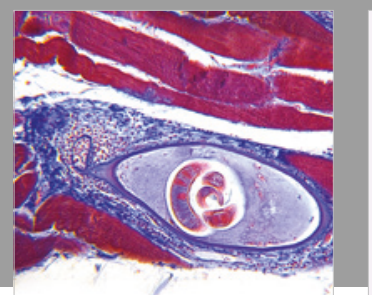

Gastroenterology Research and Practice

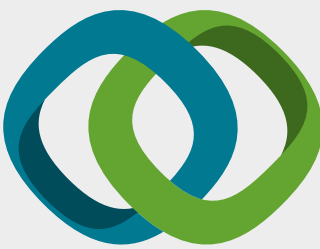

\section{Hindawi}

Submit your manuscripts at

www.hindawi.com
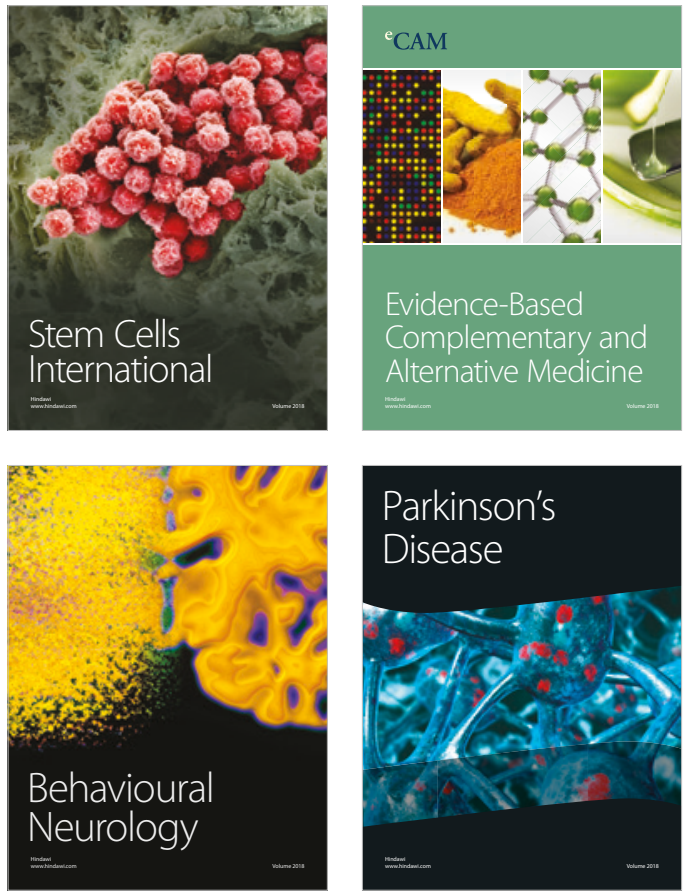

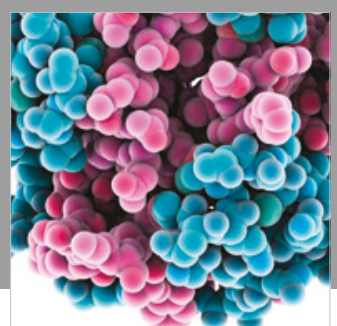

ournal of

Diabetes Research

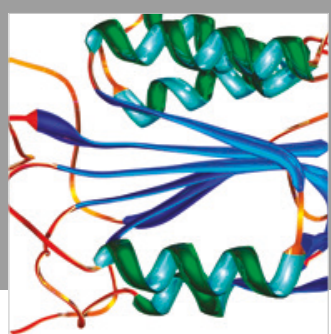

Disease Markers
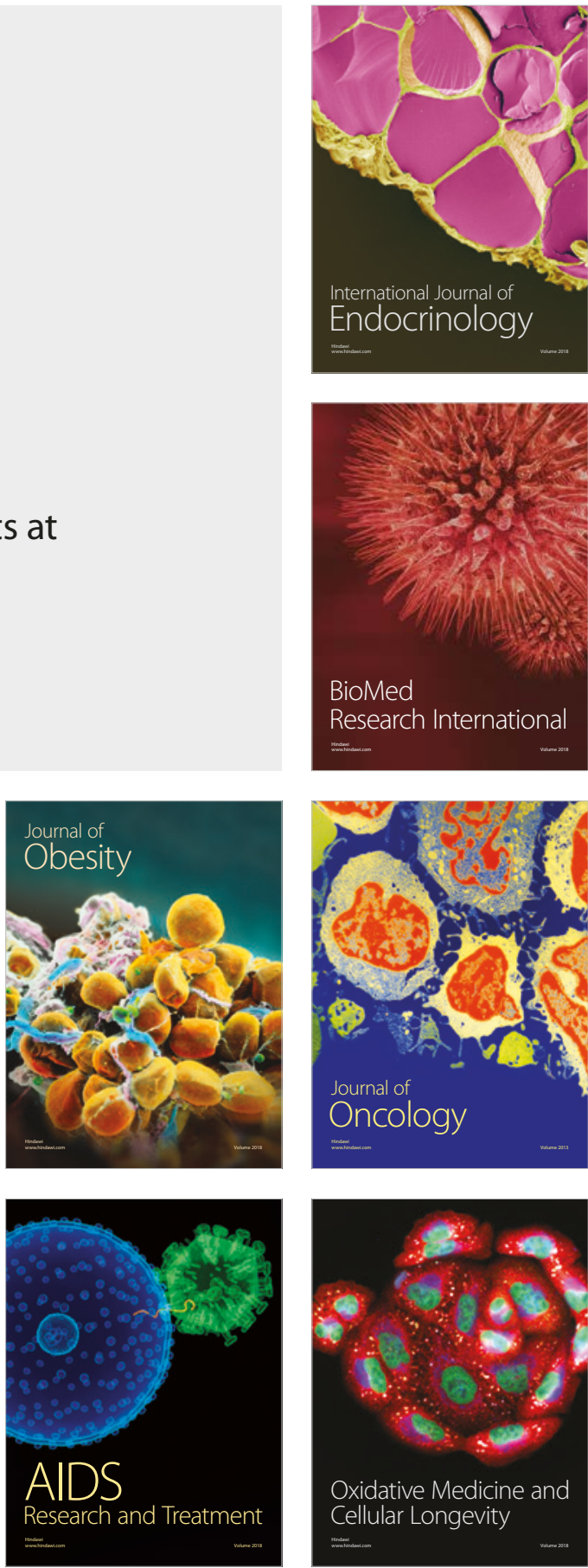